\title{
Factors Governing Pasting Properties of Waxy Wheat Flours
}

\author{
Shivananda K. Garimella Purna, ${ }^{1}$ Yong-Cheng Shi, ${ }^{1, \dagger}$ Lan Guan, ${ }^{1}$ Jeff D. Wilson, ${ }^{2}$ and Robert A. Graybosch ${ }^{3}$
}

ABSTRACT

Cereal Chem. 92(5):529-535
Waxy wheat (Triticum aestivum L.) contains endosperm starch lacking in amylose. To realize the full potential of waxy wheat, the pasting properties of hard waxy wheat flours as well as factors governing the pasting properties were investigated and compared with normal and partial waxy wheat flours. Starches isolated from six hard waxy wheat flours had similar pasting properties, yet their corresponding flours had very different pasting properties. The differences in pasting properties were narrowed after endogenous $\alpha$-amylase activity in waxy wheat flours was inhibited by silver nitrate. Upon treatment with protease, the extent of protein digestibility influenced the viscosity profile in waxy wheat flours. Waxy wheat starch granules swelled extensively when heated in water and exhibited a high peak viscosity, but they fragmented at high temperatures, resulting in more rapid breakdown in viscosity. The extensively swelled and fragmented waxy wheat starch granules were more susceptible to $\alpha$-amylase degradation than normal wheat starch. A combination of endogenous $\alpha$-amylase activity and protein matrix contributed to a large variation in pasting properties of waxy wheat flours.
Starch in endosperm of normal wheat (Triticum aestivum L.) consists of $\sim 25 \%$ amylose (mostly linear) and $\sim 75 \%$ amylopectin (highly branched), whereas starch in endosperm of waxy wheat essentially contains only amylopectin (Graybosch 2005). Waxy wheat is a potentially valuable specialty wheat. The development, unique properties, and uses of waxy wheats in noodles, bread, and tortillas have been reviewed (Graybosch 1998; Seib 2000; Chibbar and Chakraborty 2005; Hung et al. 2006; Maningat et al. 2009). Because of its increased swelling and moisture-holding capacity, the addition of waxy wheat flour may provide increased softness and extended shelf life, as well as the potential to reduce fat in bakery foods. In dry cereal foods, such as instant breakfast cereals, crackers, and salty snacks, adding waxy wheat flour has been suggested as a means to soften a product's bite and increase its friability (Maningat et al. 2009). In addition, waxy wheat flour has the potential to be wet-milled to yield two valuable coproducts, waxy wheat starch and vital wheat gluten (Guan et al. 2009). Waxy wheat starch can be converted to maltodextrins or modified to produce thickeners with a low pasting temperature and a low rate of retrogradation (Maningat et al. 2009).

When waxy wheat flours are heated in excess water, they exhibit different properties compared with normal wheat flours (Graybosch et al. 2000; Ishida et al. 2003; Kim et al. 2003; Graybosch 2005). Waxy wheat flours exhibit peak viscosity at a lower temperature than normal wheat flour (Kim et al. 2003); this property can be used as an indicator to identify waxy wheat flours. In addition, waxy wheat flours have lower final viscosity during pasting than normal wheat flours (Yasui et al. 1999; Geera et al. 2006). However, reports are conflicted on the effect of the waxy character on peak viscosity when analyzed in distilled water. Some reports suggest that waxy wheat flours have higher peak viscosity than normal wheat flours (Abdel-Aal et al. 2002; Morita et al. 2002), whereas other studies have found that normal flours have higher peak viscosity than waxy wheat flours (Morris et al. 1998; Yasui et al. 1999; Ishida et al. 2003). The discrepancies have not been well investigated. In addition, Graybosch et al. (2003) found significant genetic variation in flour peak viscosities among 19 spring waxy wheats. Thus, factors other than waxy starch per se must be influencing this trait.

† Corresponding author. Phone: +1.785.532.6771. E-mail: ycshi@ksu.edu

${ }^{1}$ Department of Grain Science and Industry, Kansas State University, Manhattan, KS, 66506, U.S.A.

${ }^{2}$ U.S. Department of Agriculture, Agricultural Research Service (USDA-ARS), Center for Grain and Animal Health Research, Manhattan, KS, 66502, U.S.A. ${ }^{3}$ USDA-ARS, University of Nebraska, Lincoln, NE, 68583, U.S.A.

http://dx.doi.org/10.1094/CCHEM-10-14-0209-R

(C) 2015 AACC International, Inc.
When examining hard waxy wheats from advanced breeding lines, we noted that different hard waxy wheat flours have different dough-mixing properties and gluten indexes (Guan et al. 2009). Our continued investigations have revealed large variations in pasting properties among hard waxy wheat flours. In addition to bakery applications (Garimella Purna et al. 2011), waxy wheat flour has the potential to be used as a thickener in foods; however, the inconsistency in pasting properties would be a concern and would affect the use of waxy wheat flours as a thickener. In light of the conflicting reports in the literature and our own observations, the objective of this study was to investigate and determine the factors governing the pasting properties of waxy wheat flours and compare their pasting properties with those of normal and partial waxy wheat flours.

\section{MATERIALS AND METHODS}

Materials. Six hard waxy wheat samples (NX03Y2114, NX03Y2115, NX03Y2205, NX03Y2315, NWX03Y2459, and NX03Y2489), one hard partial waxy wheat (Trego), and one hard normal red winter wheat (Karl 92) were used. Trego is a hard white wheat with null at the $W x-B$ locus. The single kernel characteristics of all the wheats including hardness index and the pedigrees of the waxy wheat lines were reported by Guan et al. (2009). The last four digits in each waxy sample identification are used in this paper. Wheat kernels were tempered to $16 \%$ moisture for $18 \mathrm{~h}$ and were roller-milled into straight-grade flour on a Bühler MLU 202 experimental mill (Bühler, Uzwil, Switzerland). Flour yield for all wheat samples was previously reported (Guan 2008). Starches were isolated by a dough-washing method, and protein content of the isolated starches as well as yield and recovery of the starches were previously reported (Guan et al. 2009).

Proximate Analysis and Analytical Tests on Flours. Moisture and protein contents of the eight flour samples were measured by AACC International Approved Methods 44-15.02 and 46-30.01, respectively, and were previously reported by Guan et al. (2009). Total and damaged starch contents were determined by AACCI Approved Methods 76-13.01 and 76-30.02, respectively, with assay kits from Megazyme International Ireland (Bray, Ireland). $\alpha$-Amylase activity of flours was determined by AACCI Approved Method 22-02.01 with a Megazyme assay kit. Enzyme activity was reported in Ceralpha units (CU), in which one unit of activity is defined as the amount of enzyme in the presence of excess thermostable amyloglucosidase required to release $1 \mu \mathrm{mol}$ of $p$-nitrophenol from end-blocked $p$-nitrophenyl maltoheptaoside in 1 min under the defined assay conditions. Arabinoxylan content expressed as D-xylose was determined with phloroglucinol colorimetric reagent (Douglas 1981). 
Particle Size Analysis. Particle size distribution for each flour was determined with a single-wavelength Beckman Coulter LS 13 320 particle size analyzer (Beckman Coulter, Miami, FL, U.S.A.). Each sample was analyzed in duplicate, and the mean particle size (in micrometers), assuming spherical particles, was reported.

Pasting Properties. Flour pasting properties were determined with a Rapid Visco Analyzer (RVA) (Perten Instruments North America, Springfield, IL, U.S.A.). A mixture of flour (10\% solids) in one of three solvents was prepared in an RVA canister. Final total weight in the RVA canister was $28 \mathrm{~g}$. An RVA paddle was inserted into the canister, and the mixture was gently agitated to disperse flour lumps. The RVA canister was then subjected to a 13 min RVA test to determine flour pasting properties (Deffenbaugh and Walker 1989). The RVA pasting curve profile included holding the sample at $50^{\circ} \mathrm{C}$ for $1 \mathrm{~min}$ followed by heating the sample from 50 to $95^{\circ} \mathrm{C}$ in $3 \mathrm{~min}$, holding the sample at $95^{\circ} \mathrm{C}$ for $3 \mathrm{~min}$, cooling the sample back to $50^{\circ} \mathrm{C}$ in $4 \mathrm{~min}$, and holding the sample at $50^{\circ} \mathrm{C}$ for $2 \mathrm{~min}$. The RVA curves were analyzed for pasting properties (i.e., pasting temperature, peak viscosity, viscosity at trough, final viscosity, and setback viscosity) with Thermocline for Windows 3 software provided with the RVA. Pasting temperature was obtained by using the function TempAtViscRate $(1,6,0,1,50)$. Setback viscosity was calculated as difference between final viscosity and viscosity at trough.

Three solvents were used: distilled water, $1 \mathrm{mM}$ silver nitrate $\left(\mathrm{AgNO}_{3}\right)$ solution, and $1 \mathrm{mM} \mathrm{AgNO}_{3}$ solution plus protease from Streptomyces griseus (P-5147, 4.5 units/mg of protein, Sigma, St. Louis, MO, U.S.A.). The effect of protease on pasting properties of flours was measured as described by Zhu et al. (2010). Flours ( $2.8 \mathrm{~g}, \mathrm{db}$ ) were suspended in water $(12.5 \mathrm{~g})$ containing $18 \mathrm{mg}$ of protease and incubated at $37^{\circ} \mathrm{C}$ for $30 \mathrm{~min}$. Subsequently, $2 \mathrm{mM} \mathrm{AgNO}_{3}$ was added to the protease-hydrolyzed flour for a total weight of $28 \mathrm{~g}$. The objective of adding $\mathrm{AgNO}_{3}$ was to inhibit the action of $\alpha$-amylase on flours during the RVA test, thereby enabling us to study the specific effects of protease on flour.

Pasting properties of isolated starches were determined at $7 \%$ solids in water or a solution containing $0.01 \% \alpha$-amylase from porcine pancreas (A-3176, Sigma).

In a separate experiment, flour samples ( $10 \%$ solids) were treated with protease in $\mathrm{AgNO}_{3}$ solution (containing $18 \mathrm{mg}$ of protease) at $30^{\circ} \mathrm{C}$ for $30 \mathrm{~min}$. The final weight of the flour sample and proteasecontaining $\mathrm{AgNO}_{3}$ solution was $28 \mathrm{~g}$. Subsequently, an aliquot $(1 \mathrm{~mL})$ of the flour suspension was centrifuged at $10,000 \times g$ and the supernatant was discarded. The residual protein in the pellet was analyzed with a LECO FP-428 nitrogen determinator (LECO, St. Joseph, MI, U.S.A.) and expressed as a percentage of the original protein content of the samples. Each sample was analyzed in duplicate.

Gel Permeation Chromatography (GPC) of Debranched Starches. Starch $(20 \mathrm{mg})$ was added to $10 \mathrm{~mL}$ of $0.01 \mathrm{M}$ acetate buffer at $\mathrm{pH} 4.0$ in a $12 \mathrm{~mL}$ glass vial with a microstirring bar. The vial was placed in a boiling water bath on a stir plate for $1 \mathrm{~h}$. Isoamylase $(50 \mu \mathrm{L})(\mathrm{EC}$ 3.2.1.68, Hayashibara Biochemical Laboratories, Okayama, Japan) was added to the solution after cooling to room temperature. The vial was placed at $50^{\circ} \mathrm{C}$ in a water bath overnight, frozen in a dry ice/acetone bath, and freeze-dried. The freeze-dried debranched starch $(4 \mathrm{mg}$, db) was dissolved in $4 \mathrm{~mL}$ of dimethyl sulfoxide by heating in a boiling water bath for $24 \mathrm{~h}$ with constant stirring. GPC analysis was performed with a Polymer Laboratories PL-GPC 220 integrated GPC/size-exclusion chromatography fully automated system (Polymer Laboratories, Amherst, MA, U.S.A.) as previously described (Cai et al. 2010).

Light Microscopy. The changes in morphology of starch granules during heating in water were examined by light microscopy. Starch $(0.1 \mathrm{~g})$ was added to distilled water $(10 \mathrm{~mL})$ and dispersed by using a vortex mixer. A small amount of highvacuum grease (Dow Corning, Midland, MI, U.S.A.) was spread evenly as an extremely thin layer around the edge of a squareshaped coverslip. One drop of the starch suspension was transferred onto a slide and covered by the coverslip. The starch was viewed with an Olympus BX51 microscope (Olympus America, Melville, NY, U.S.A.) equipped with an STC200 hot stage. Images and photographs were captured under $\times 40$ objective with a SPOT Insight camera and SPOT 4.6 for Windows software (Diagnostic Instruments, Sterling Heights, MI, U.S.A.). The heating rate was set at $5^{\circ} \mathrm{C} / \mathrm{min}$.

Thermal Properties of Flours. Thermal properties of flours were determined by differential scanning calorimetry (DSC) (Q100 DSC, TA Instruments, New Castle, DE, U.S.A.). For gelatinization properties, each flour sample and distilled water were added to the DSC pan in a 1:2 ratio (w/w). The pan was hermitically sealed and held at $25^{\circ} \mathrm{C}$ for $24 \mathrm{~h}$. The samples were then heated from 10 to $140^{\circ} \mathrm{C}$ at $10^{\circ} \mathrm{C} / \mathrm{min}$. An empty DSC pan was used as a reference. Onset, peak, and end temperature along with enthalpy were determined. Each sample was analyzed in duplicate, and mean values were reported.

Statistical Analysis. MacAnova 4.12 software (School of Statistics, University of Minnesota, Minneapolis, MN, U.S.A.) was used to perform ANOVA and Tukey's honest significance difference analysis. The level of significance was $P<0.05$ throughout the paper. Each sample was analyzed at least in duplicate.

\section{RESULTS AND DISCUSSION}

Composition and Particle Size of Flours. Protein content of waxy wheat flours ranged from 12.0 to $15.1 \%(\mathrm{db})$, whereas the normal wheat flour (Karl 92) and the partial waxy wheat flour (Trego) had protein contents of 15.47 and $14.04 \%$ (db), respectively (Guan et al. 2009; Table I). The protein content of Karl 92 was significantly higher than most of the waxy wheat flours except for sample 2205. Total starch content of the six waxy wheat flours was between 75.0 and $81.7 \%$ (db), whereas Karl 92 and Trego had

TABLE I

Damaged Starch, Arabinoxylan Content, and $\alpha$-Amylase Activity of Wheat Flours ${ }^{y}$

\begin{tabular}{lcccccc}
\hline Sample & Protein Content $^{\mathbf{z}}(\boldsymbol{\%})$ & $\begin{array}{c}\text { Total Starch } \\
\text { Content }^{\mathbf{z}}(\boldsymbol{\%})\end{array}$ & $\boldsymbol{\%}$ Damaged Starch & $\begin{array}{c}\text { \% Arabinoxylan Content } \\
(\text { as D-Xylose })\end{array}$ & $\begin{array}{c}\boldsymbol{\alpha} \text {-Amylase Activity } \\
(\mathbf{C U} / \mathbf{g})\end{array}$ & $\begin{array}{c}\text { Mean Flour Particle } \\
\text { Size }(\boldsymbol{\mu m})\end{array}$ \\
\hline 2114 & $13.88 \pm 0.1 \mathrm{~b}$ & 75.0 & $6.02 \pm 0.10 \mathrm{e}$ & $1.73 \pm 0.15 \mathrm{a}$ & $0.12 \pm 0.03 \mathrm{bc}$ & $34 \pm 0.6 \mathrm{f}$ \\
2115 & $13.78 \pm 0.1 \mathrm{~b}$ & 81.7 & $8.98 \pm 0.07 \mathrm{bc}$ & $1.78 \pm 0.29 \mathrm{a}$ & $0.20 \pm 0.02 \mathrm{a}$ & $37 \pm 0.2 \mathrm{e}$ \\
2205 & $15.10 \pm 0.0 \mathrm{a}$ & 78.3 & $10.08 \pm 0.03 \mathrm{~b}$ & $1.36 \pm 0.09 \mathrm{a}$ & $0.09 \pm 0.01 \mathrm{~cd}$ & $54 \pm 0.1 \mathrm{a}$ \\
2315 & $12.00 \pm 0.0 \mathrm{e}$ & 81.7 & $8.52 \pm 0.25 \mathrm{c}$ & $2.05 \pm 0.42 \mathrm{a}$ & $0.14 \pm 0.02 \mathrm{~b}$ & $47 \pm 0.0 \mathrm{~b}$ \\
2459 & $13.33 \pm 0.2 \mathrm{c}$ & 78.3 & $11.38 \pm 0.69 \mathrm{a}$ & $1.65 \pm 0.09 \mathrm{a}$ & $0.13 \pm 0.00 \mathrm{~b}$ & $42 \pm 0.0 \mathrm{~d}$ \\
2489 & $12.82 \pm 0.1 \mathrm{~d}$ & 80.0 & $9.33 \pm 0.04 \mathrm{bc}$ & $1.59 \pm 0.09 \mathrm{a}$ & $0.08 \pm 0.01 \mathrm{de}$ & $41 \pm 0.2 \mathrm{~d}$ \\
Karl 92 & $15.47 \pm 0.0 \mathrm{a}$ & 76.7 & $7.19 \pm 0.35 \mathrm{~d}$ & $1.69 \pm 0.05 \mathrm{a}$ & $0.03 \pm 0.00 \mathrm{f}$ & $45 \pm 0.1 \mathrm{c}$ \\
Trego & $14.04 \pm 0.2 \mathrm{~b}$ & 76.7 & $6.77 \pm 0.06 \mathrm{de}$ & $1.26 \pm 0.08 \mathrm{a}$ & $0.04 \pm 0.00 \mathrm{ef}$ & $46 \pm 0.5 \mathrm{c}$ \\
\hline
\end{tabular}

${ }^{\mathrm{y}}$ Mean \pm SD values are reported. Means not sharing the same letter within each column are significantly different $(P<0.05)$. Full sample identification numbers: NX03Y2114, NX03Y2115, NX03Y2205, NX03Y2315, NWX03Y2459, and NX03Y2489. CU = Ceralpha unit.

z Values reported by Guan et al. (2009). 
$76.7 \%(\mathrm{db})$, as reported by Guan et al. (2009). Although starch content of wheat flours varied, no correlation emerged between starch content and pasting properties, as discussed in the next section. Other factors besides starch content affected the pasting properties of wheat flours.

Damaged starch values for flours ranged from 6.02 to $11.38 \%$ (Table I). Most waxy wheat flours had significantly higher damaged starch content than the normal wheat flour and partial waxy wheat flour. This could be owing to greater susceptibility of waxy wheat to mechanical damage during milling (Bettge et al. 2000). No significant differences were present in arabinoxylan content between Karl 92 and waxy wheat flours (Table I). Our results differ from those of Sayaslan et al. (2006), who reported 20-30\% higher arabinoxylan (pentosan) content in waxy wheat samples than in normal wheat flour (Karl 92). The underlying reasons for the different results are unclear but could be owing to the different cultivars used in the pedigree of waxy wheat lines in this study or owing to differences in cultural environments.

Except for sample 2489, waxy wheat flours exhibited significantly higher $\alpha$-amylase activity compared with normal wheat flour (Karl 92) and partial waxy wheat flour (Trego). Among waxy wheat flours, sample 2115 had the highest $\alpha$-amylase activity $(0.20 \mathrm{CU} / \mathrm{g})$, and sample 2489 had the lowest $\alpha$-amylase activity $(0.08 \mathrm{CU} / \mathrm{g})$, whereas normal wheat flour (Karl 92) had an $\alpha$-amylase activity of $0.033 \mathrm{CU} / \mathrm{g}$.

Mean particle size of all eight flours varied within a narrow range of 34-54 $\mu \mathrm{m}$ (Table I), which is within the range of medium fraction for flours (Wang and Flores 2000). Flour particle size could influence both the extent of starch damage (Wang and Flores 2000) and subsequent enzyme activity in our proposed RVA studies.

Debranched waxy wheat starch showed a bimodal distribution with similar proportions of the two fractions as debranched normal wheat starch (curves almost overlaying on top of each other, data not shown), indicating that the molecular structure of the waxy wheat starch was close to that of amylopectin in the normal wheat starch. Reports of the amylopectin structure of waxy wheats and their parent lines have conflicted. Hayakawa et al. (1997) reported that amylopectin in waxy wheat starch had significantly higher degree of polymerization values than amylopectin in starch isolated from their parent lines (nonwaxy wheat). In a more recent study, Yoo and Jane (2002) showed that waxy wheat amylopectin lacked the extralong branched chains that are present in normal wheat, whereas Yasui et al. (1996) reported similar amylopectin chain length distribution profiles for both waxy and parent lines. In our study, we observed little difference in amylopectin chain length distribution among the advanced waxy wheat lines.

Pasting Properties of Flours. Pasting properties of flours in different solutions are given in Table II and Figure 1. In all solvents, the waxy wheat flours exhibited lower pasting temperatures $\left(\sim 70^{\circ} \mathrm{C}\right)$ than normal wheat flour $\left(\sim 90^{\circ} \mathrm{C}\right)$. To compare the whole pasting profile, one waxy wheat flour (sample 2489) that had a low viscosity and another waxy wheat flour (sample 2115) that had a high viscosity in water were selected and compared with normal wheat flour (Fig. 1).

Distilled Water. Waxy wheat flours had a significantly lower peak temperature $\left(\sim 67^{\circ} \mathrm{C}\right)$ in water than normal $\left(93^{\circ} \mathrm{C}\right)$ and partial waxy wheat flours $\left(91^{\circ} \mathrm{C}\right)$. No significant differences were observed in the pasting temperatures among waxy wheat flours. The low pasting and peak temperatures for these waxy wheat flours agreed with previous findings on waxy wheat flours (Yasui et al. 1999; Ishida et al. 2003) and isolated waxy wheat starches (Hayakawa et al. 1997; Sasaki et al. 2000; Grant et al. 2001; Kim et al. 2003).

We observed remarkable variations in peak viscosity for waxy wheat flours in water, ranging from $472 \mathrm{cP}$ (sample 2489) to $2,011 \mathrm{cP}$ (sample 2205) (Table II). Samples 2114 and 2205 had peak viscosities similar to Karl 92, but the rest of the waxy wheat flours had significantly lower peak viscosities than Karl 92. Among waxy wheat flours, sample 2489 exhibited the lowest peak viscosity despite low $\alpha$-amylase activity.

Waxy wheat flours had significantly lower trough (hot paste) viscosity and exhibited greater breakdown compared with normal and partial waxy wheat flours. The great reduction in the viscosity

TABLE II

Pasting Properties of Wheat Flours in Different Solvents $(N=2)^{\mathrm{y}}$

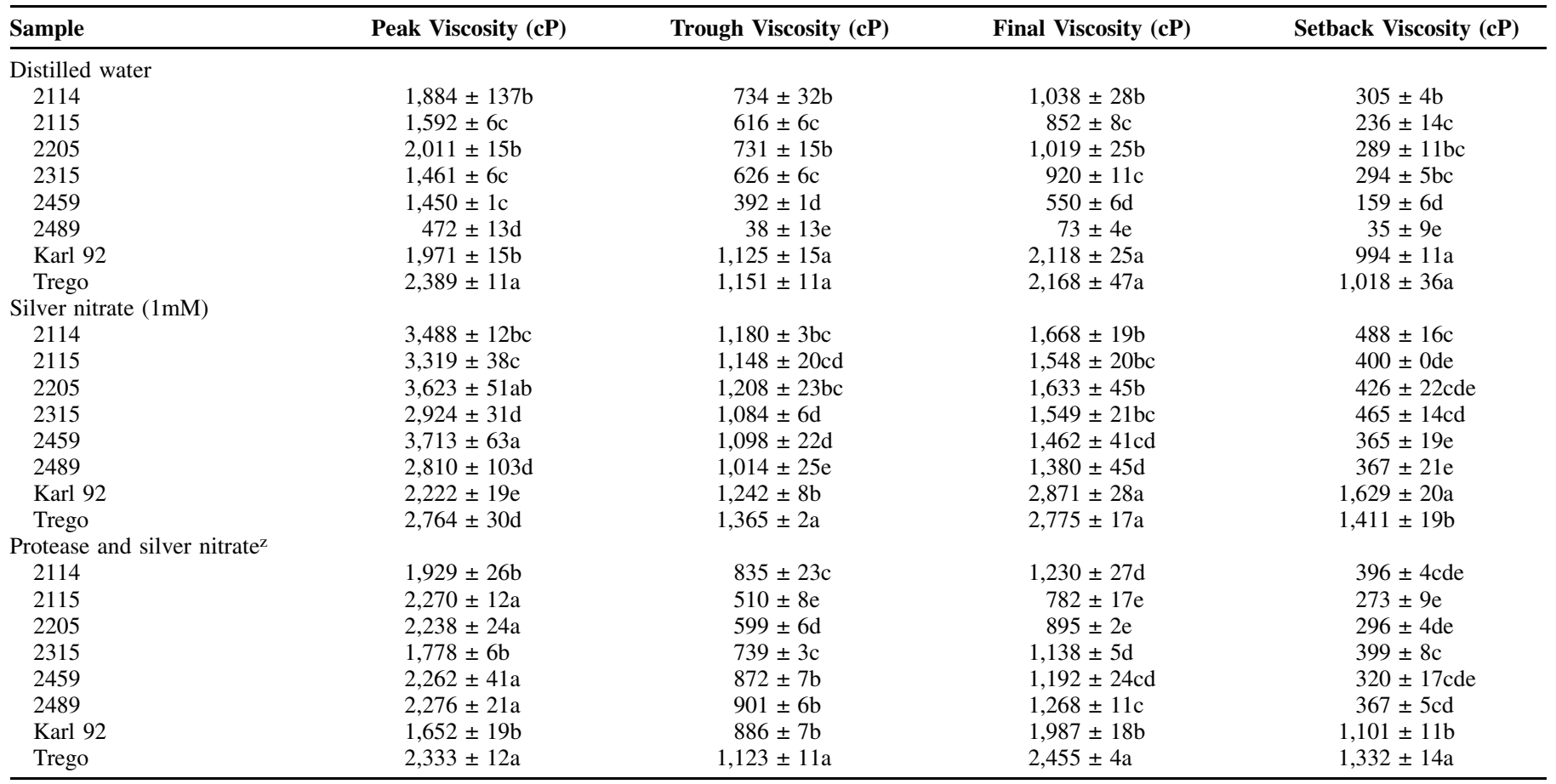

y Mean \pm SD values are reported. Means not sharing the same letter within each column are significantly different $(P<0.05)$. Full sample identification numbers: NX03Y2114, NX03Y2115, NX03Y2205, NX03Y2315, NWX03Y2459, and NX03Y2489.

${ }^{\mathrm{z}}$ Flours digested with protease $(80 \mathrm{U})$ pasted in silver nitrate $(1 \mathrm{mM})$. 
of waxy wheat flours could be owing to the lack of granular rigidity of waxy wheat starches when heated in excess water (Guan 2008). Final viscosity of waxy wheat flours was significantly lower than Trego and Karl 92 flours (Table II), which could be attributed to the lack of amylose in waxy wheat flours and thus the inability to form a gel matrix (Leloup et al. 1991). Because of the lack of amylose, the setback viscosities of the waxy wheat flours were much lower than those of the normal and partial waxy wheat flours (Table II).

Silver Nitrate Solution. To examine the influence of $\alpha$-amylase activity, pasting properties of flours were analyzed in the presence

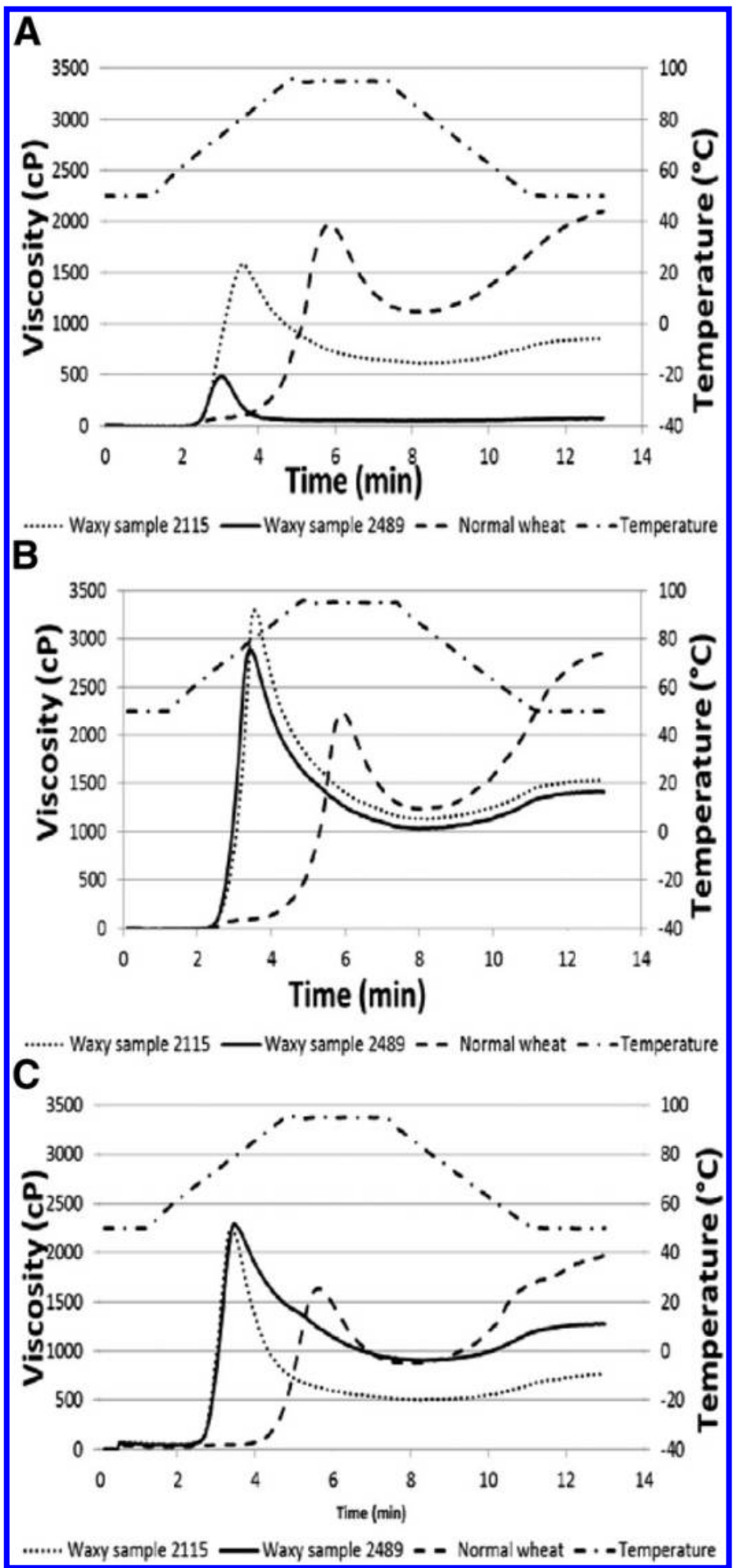

Fig. 1. Rapid Visco Analyzer pasting properties of waxy and normal wheat flours: $\mathbf{A}$, in distilled water; $\mathbf{B}$, in $1 \mathrm{mM}$ silver nitrate solution; and C, flours digested with protease and pasted in $1 \mathrm{mM}$ silver nitrate. of $\mathrm{AgNO}_{3}$ (Fig. 1B). Previous researchers have utilized silver nitrate solution to inhibit $\alpha$-amylase activity in sprouted and normal wheat flours (Crosbie and Lambe 1993; Bhattacharya and Corke 1996; Batey et al. 1997; Bhattacharya et al. 1997; Yasui et al. 1999; Abdel-Aal et al. 2002; Mariotti et al. 2005). We observed an increase in peak viscosity for all wheat flours when $\alpha$-amylase activity was inhibited, but the overall increase in pasting properties was greater in waxy wheat flours compared with normal and partial waxy wheat flours (Table II, Fig. $1 \mathrm{~A}$ and $\mathrm{B})$. Peak viscosity of the waxy wheat flours was significantly higher than normal wheat flour when tested in the presence of $\mathrm{AgNO}_{3}$. The differences in peak viscosities among waxy wheat flours were narrowed when $\alpha$-amylase activity was inhibited. Our results suggest that waxy flours were more susceptible to amylolytic degradation than normal wheat flour, but the extent of degradation differed among the waxy wheat flours. To understand the full scope of amylolytic degradation in waxy wheat flour, separate studies on isolated waxy wheat starches were conducted and are reported in the following section.

The hot paste viscosity and final viscosity of the waxy wheat flours were still lower than that of the normal and partial waxy wheat flours in silver nitrate solution (Table II), reflecting the larger breakdown of the waxy wheat flours. The final viscosity and setback viscosity of the waxy wheat flours were also lower (Table II) owing to the lack of amylose.

Pasting Properties of Isolated Starches and Their Susceptibility to $\alpha$-Amylase. Starch is the major flour component and is largely responsible for pasting properties of flour. Hence, starches were isolated from flours, and their pasting properties were determined. Interestingly, starches isolated from the six waxy wheat flours had similar pasting properties (Fig. 2). Waxy wheat starch had a greater increase in viscosity at a lower temperature than normal wheat starch, indicating that waxy wheat starch developed viscosity more rapidly. In fact, the peak viscosity of the waxy wheat starches was more than 2.5 times higher than that of the normal wheat starch. Baik and Lee (2003) reported that the peak viscosity was greater than 1,780 BU for two waxy wheat starches but only $210 \mathrm{BU}$ for a normal wheat starch at $8.9 \%$ starch solids. Amylopectin has been suggested to be responsible for swelling of starch granules (Tester and Morrison 1990), whereas amylose and amylose-lipid complex inhibit granule swelling (Tester and Morrison 1990, 1992; Sasaki and Matsuki 1998). The high peak viscosity of waxy wheat starch suggests that it has great potential to be used as a base starch to make modified starch products as thickeners in food applications. The large breakdown in viscosity can be eliminated or reduced by chemical cross-linking of waxy wheat starch (Reddy and Seib 2000).

To further understand the susceptibility of waxy wheat starches to enzyme activity, low levels of exogenous $\alpha$-amylase $(0.01 \% \mathrm{v} / \mathrm{w})$ were added to starches isolated from waxy wheat and normal wheat (Karl 92). We observed a significant decrease in paste viscosity of waxy wheat starch but only a small change in pasting properties of normal wheat starch (Fig. 3). The final viscosity of normal wheat starch decreased from about 1,000 to $750 \mathrm{cP}$, whereas the final viscosity of waxy wheat starch dropped from about $1,250 \mathrm{cP}$ to less than $100 \mathrm{cP}$. The greater loss in viscosity further validated the point that waxy wheat starches were more susceptible to $\alpha$-amylase activity than normal wheat starch. The added $\alpha$-amylase was not a thermostable enzyme but active at $60-80^{\circ} \mathrm{C}$. Waxy wheat starch swelled more at lower temperatures $\left(60-80^{\circ} \mathrm{C}\right)$ and thus was more prone to $\alpha$-amylase hydrolysis.

Our hot-stage microscopic results (Fig. 4) demonstrate the fate of starch granules of waxy and normal wheat upon heating in excess water and help to understand the pasting properties of the starches. At $73^{\circ} \mathrm{C}$, normal wheat starch granules maintained granular integrity, whereas waxy starch granules swelled excessively and lost their granular integrity. These observations help to explain the large 
breakdown in the pasting profiles of the waxy wheat flours (Fig. 1) and starches (Fig. 2) and the aberrant falling numbers of waxy wheat flours observed by Graybosch et al. (2000). Significant swelling of granules contributed to the high peak viscosity of waxy wheat starch (Fig. 2). Excessive swelling and loss of granular integrity probably contribute to the sticky and soft texture of cooked white salted noodles prepared from waxy wheat flours (Baik and Lee 2003).

Silver Nitrate and Protease Solution. To assess the role of protein in flour pasting properties, flour samples were treated with protease and then pasted in $\mathrm{AgNO}_{3}$ solution (Fig. 1C). Peak viscosities for all flours digested with protease and pasted in $\mathrm{AgNO}_{3}$ solution were lower than that in $\mathrm{AgNO}_{3}$ solution without protease treatment. In addition, peak viscosities of waxy wheat flours in protease plus $\mathrm{AgNO}_{3}$ solution were significantly higher than normal wheat flour. Debet and Gidley (2007) have suggested that starch swelling properties are affected owing to surface protein (likely storage protein) adsorbed onto the surface of starch granules. In cereal flour, the protein matrix could protect the starch granules from mechanical damage during pasting (Hamaker and Griffin 1993). Our results suggest that in flours, protease action could destroy the protein matrix and facilitate mechanical destruction of waxy starch granules during pasting.
When waxy wheat flours were treated with protease and pasted in $\mathrm{AgNO}_{3}$ solution, their peak viscosities became similar (Table II; Fig. 1C); however, differences in viscosity profiles of waxy wheat flours persisted. To understand the effects of protein on pasting properties, we determined residual protein in the pastes. For instance, $\sim 60 \%$ of flour protein in sample 2115 was solubilized by protease in the 30 min digestion period, whereas only $52 \%$ of the flour protein was solubilized in sample 2489. The extensive proteolysis could have weakened the interaction between starch granules and protein, making the starch more susceptible to shear thinning. After the protein in flour was essentially removed, the isolated starches from all the waxy wheat starches demonstrated similar pasting properties (Fig. 2).

To confirm that the changes in pasting properties after the protease treatment were because of its action on protein in the flours but not because of any amylase activity in the protease, we used the same level of protease to treat a waxy maize starch at $37^{\circ} \mathrm{C}$ for $30 \mathrm{~min}$ and found that the pasting viscosity of the waxy maize starch was not changed after the protease treatment.

Thermal Properties of Flour. Although gelatinization temperatures for normal and partial waxy wheat flours were slightly $\left(1-2^{\circ} \mathrm{C}\right)$ lower than the waxy wheat flours (Table III), an apparent amylose-lipid complex peak was present at $\sim 100^{\circ} \mathrm{C}$ but

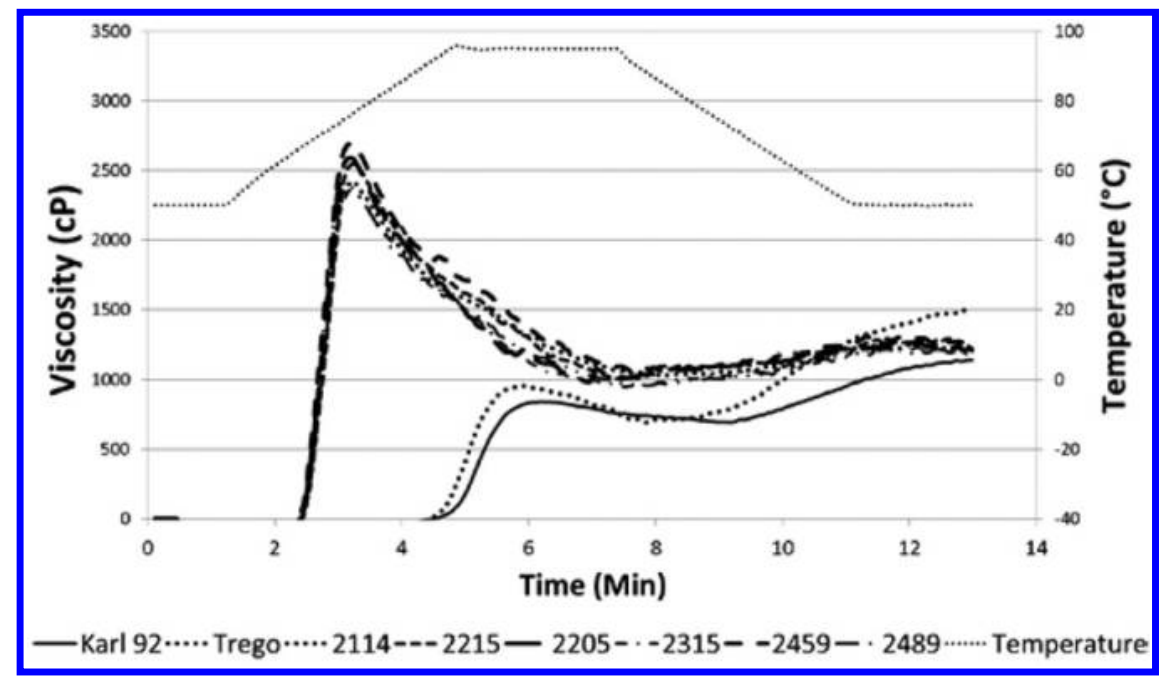

Fig. 2. Rapid Visco Analyzer pasting properties of waxy wheat starch (samples 2114, 2115, 2205, 2315, 2459, and 2489), normal wheat starch (Karl 92), and partial waxy wheat starch (Trego) determined at $7 \%$ solids.

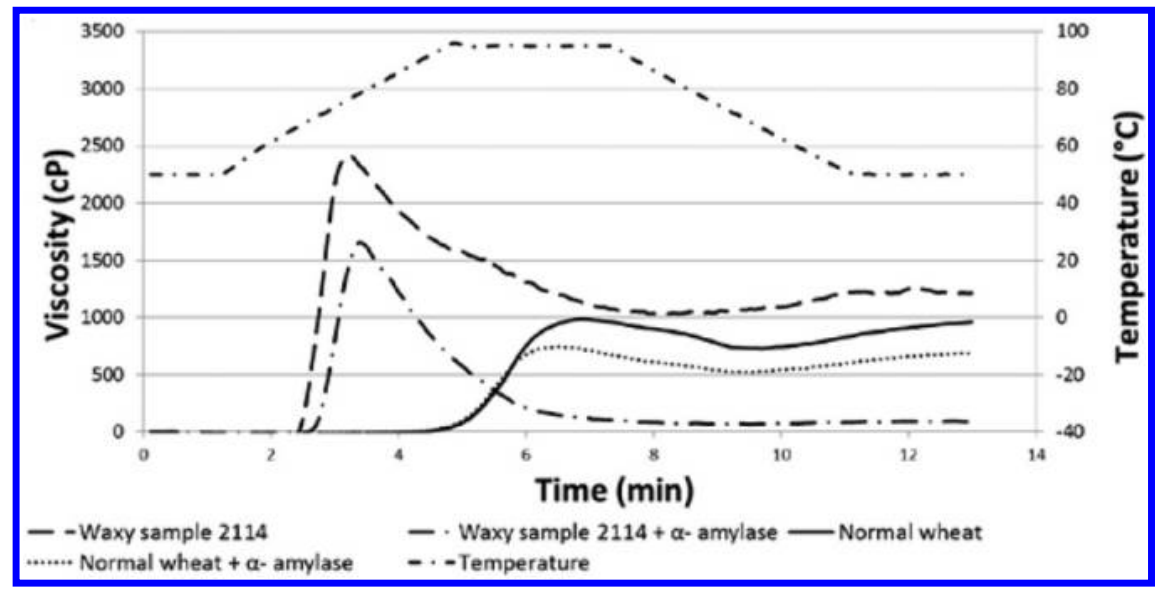

Fig. 3. Rapid Visco Analyzer pasting properties of isolated starches from waxy and normal wheat flours with and without addition of $0.01 \% \alpha$-amylase. 
was absent in waxy wheat samples (data not shown). The results help explain the lower pasting peak temperatures of waxy wheat flours compared with normal (Karl 92) or partial waxy (Trego) wheat flour (Fig. 1). A lack of amylose enables waxy wheat flours to swell extensively at their gelatinization temperature and exhibit a peak viscosity at about the same temperature $\left(\sim 70^{\circ} \mathrm{C}\right)$. In contrast, amylose and the amylose-lipid complex inhibit the swelling of starch granules (Tester and Morrison 1990, 1992; Sasaki and Matsuki 1998) in normal and partial waxy wheat flours. As a result, normal wheat flour had a higher pasting temperature than waxy wheat flours (Fig. 1) even though the gelatinization temperature of the normal wheat flour as determined by DSC was slightly lower (Table III).

\section{CONCLUSIONS}

At least two factors (protein matrix and susceptibility to $\alpha$-amylase activity) contribute to the wide range of pasting properties of waxy wheat flours. Waxy wheat flours are more prone to endogenous $\alpha$-amylase degradation than normal and partial waxy wheat flours. Isolated waxy wheat starches that no longer contained $\alpha$-amylase activity had similar pasting properties. The protein matrix may affect the swelling of starch granules and, in turn, cause variations in pasting properties of waxy wheat flours. Waxy wheat starch had lower pasting temperatures but more than 2.5 times higher peak viscosity than the normal wheat starch, and it can be used as a base starch to produce modified starch products with better thickening power.

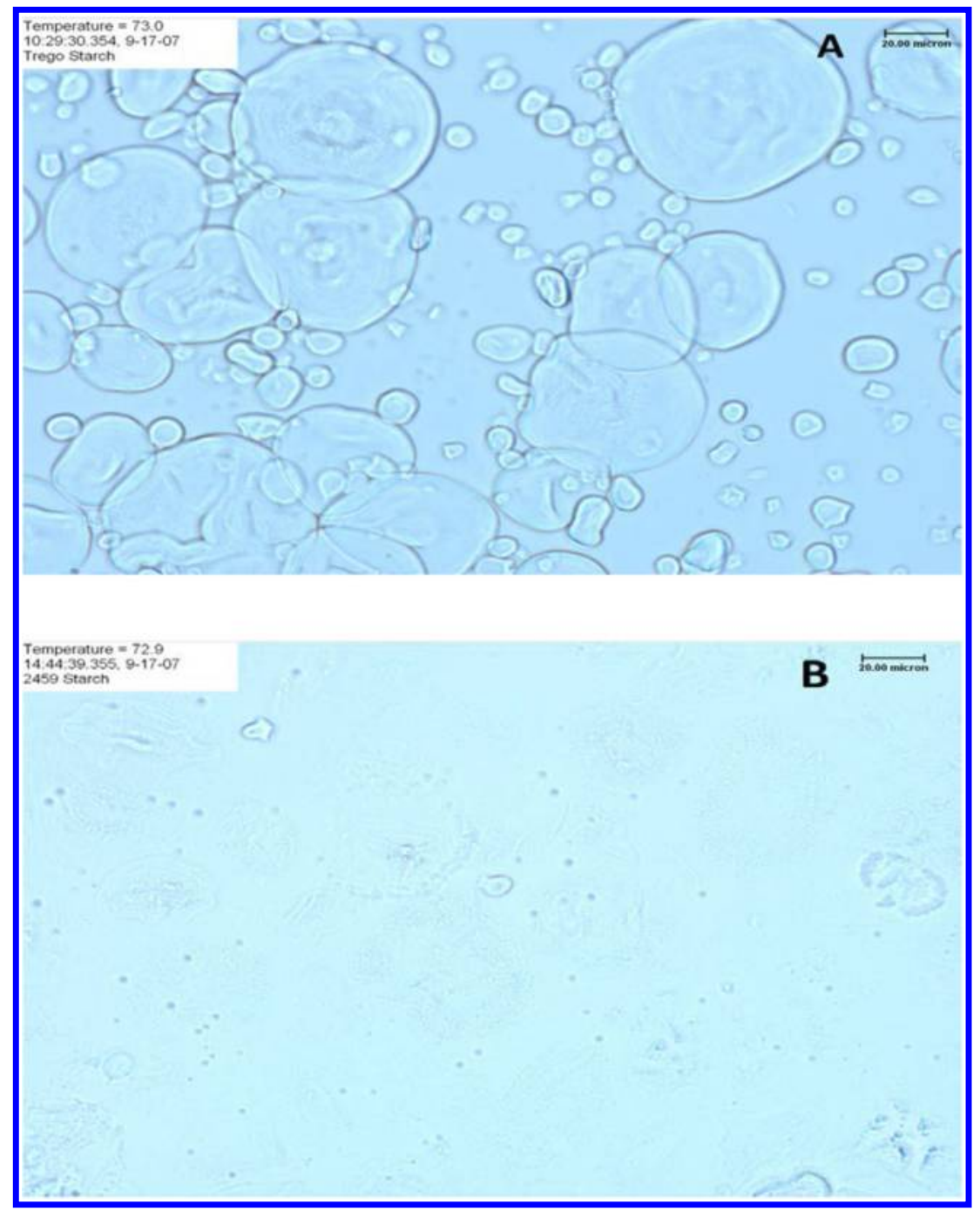

Fig. 4. Granule morphology at $73^{\circ} \mathrm{C}$ for normal (A) and waxy (B) wheat starches. The bar in the photographs is $20 \mu \mathrm{m}$.

TABLE III

Gelatinization Properties of Flours (33.3\% Solids) Determined by Differential Scanning Calorimeter $(N=2)^{\mathrm{z}}$

\begin{tabular}{lcccc}
\hline Sample & Onset Temperature $\left({ }^{\circ} \mathbf{C}\right)$ & Peak Temperature $\left({ }^{\circ} \mathbf{C}\right)$ & End Temperature $\left({ }^{\circ} \mathbf{C}\right)$ & Enthalpy $(\Delta \boldsymbol{H}, \mathbf{J} / \mathbf{g})$ \\
\hline 2114 & $61.3 \pm 0.37 \mathrm{a}$ & $69.3 \pm 0.52 \mathrm{a}$ & $81.1 \pm 0.78 \mathrm{ab}$ & $8.0 \pm 0.19 \mathrm{a}$ \\
2115 & $61.2 \pm 0.49 \mathrm{a}$ & $69.6 \pm 0.55 \mathrm{a}$ & $80.8 \pm 0.06 \mathrm{bc}$ & $8.2 \pm 0.55 \mathrm{a}$ \\
2205 & $62.0 \pm 0.18 \mathrm{ab}$ & $70.0 \pm 0.46 \mathrm{a}$ & $82.6 \pm 0.17 \mathrm{ab}$ & $8.3 \pm 0.38 \mathrm{a}$ \\
2315 & $62.0 \pm 0.10 \mathrm{ab}$ & $70.6 \pm 0.42 \mathrm{a}$ & $84.7 \pm 0.47 \mathrm{ab}$ & $0.68 \mathrm{a}$ \\
2459 & $61.8 \pm 0.60 \mathrm{a}$ & $70.6 \pm 0.69 \mathrm{a}$ & $82.9 \pm 0.88 \mathrm{ab}$ & $7.6 \pm 0.24 \mathrm{~b}$ \\
2489 & $61.9 \pm 0.01 \mathrm{a}$ & $70.0 \pm 0.08 \mathrm{a}$ & $78.2 \pm 0.00 \mathrm{~cd}$ & $6.2 \pm 0.52 \mathrm{~b}$ \\
Karl 92 & $60.4 \pm 0.22 \mathrm{~b}$ & $66.1 \pm 0.17 \mathrm{~b}$ & $79.0 \pm 0.40 \mathrm{~d}$ & $6.8 \pm 0.35 \mathrm{ab}$ \\
Trego & $60.1 \pm 0.16 \mathrm{~b}$ & $66.1 \pm 0.01 \mathrm{~b}$ & \\
\hline
\end{tabular}

${ }^{\mathrm{z}}$ Mean \pm SD values are reported. Means not sharing the same letter within each column are significantly different $(P<0.05)$. Full sample identification numbers: NX03Y2114, NX03Y2115, NX03Y2205, NX03Y2315, NWX03Y2459, and NX03Y2489. 


\section{ACKNOWLEDGMENTS}

We thank Bryan Glazer (American Institute of Baking) for his help with RVA, Sajid Alavi for the use of DSC equipment, Kevin Fay (USDA-ARS, Manhattan, KS) for protein analysis, and Paul Seib, Chao-Feng Hsieh, and Michael Sweedman for reviewing the manuscript. This is contribution number 15-120-J from the Kansas Agricultural Experiment Station.

\section{LITERATURE CITED}

AACC International. Approved Methods of Analysis, 11th Ed. Method 22-02.01. Measurement of $\alpha$-amylase in plant and microbial materials using the Ceralpha method. Approved October 17, 2001. Method 4415.02. Moisture-Air-oven methods. Approved October 30, 1975; reapproved November 3, 1999. Method 46-30.01. Crude protein-Combustion method. Approved November 8, 1995. Method 76-13.01. Total starch assay procedure (Megazyme amyloglucosidase/ $\alpha$-amylase method). Approved November 8, 1995. Method 76-30.02. Determination of damaged starch. Approved May 1, 1969; reapproved November 3, 1999. Available online only. AACCI: St. Paul, MN.

- Abdel-Aal, E.-S. M., Hucl, P., Chibbar, R. N., Han, H. L., and Demeke, T. 2002. Physicochemical and structural characteristics of flours and starches from waxy and nonwaxy wheats. Cereal Chem. 79:458-464.

Baik, B.-K., and Lee, M.-R. 2003. Effects of starch amylose content of wheat on textural properties of white salted noodles. Cereal Chem. 80:304-309.

Batey, I. L., Curtin, B. M., and Moore, S. A. 1997. Optimization of RapidVisco Analyser test conditions for predicting Asian noodle quality. Cereal Chem. 74:497-501.

Bettge, A. D., Giroux, M. J., and Morris, C. F. 2000. Susceptibility of waxy starch granules to mechanical damage. Cereal Chem. 77:750-753.

Bhattacharya, M., and Corke, H. 1996. Selection of desirable starch pasting properties in wheat for use in white salted or yellow alkaline noodles. Cereal Chem. 73:721-728.

Bhattacharya, M., Jafari-Shabestari, J., Qualset, C. O., and Corke, H. 1997. Diversity of starch pasting properties in Iranian hexaploid wheat landraces. Cereal Chem. 74:417-423.

Cai, L., Shi, Y.-C., Rong, L., and Hsiao, B. S. 2010. Debranching and crystallization of waxy maize starch in relation to enzyme digestibility. Carbohydr. Polym. 81:385-393.

Chibbar, R. N., and Chakraborty, M. 2005. Characteristics and uses of waxy wheat. Cereal Foods World 50:121-126.

Crosbie, G. B., and Lambe, W. J. 1993. The application of the flour swelling volume test for potential noodle quality to wheat breeding lines affected by sprouting. J. Cereal Sci. 18:267-276.

Debet, M. R., and Gidley, M. J. 2007. Why do gelatinized starch granules not dissolve completely? Roles for amylose, protein, and lipid in granule "ghost" integrity. J. Agric. Food Chem. 55:4752-4760.

$\checkmark$ Deffenbaugh, L. B., and Walker, C. E. 1989. Comparison of starch pasting properties in the Brabender Viscoamylograph and the Rapid Visco-Analyzer. Cereal Chem. 66:493-499.

Douglas, S. G. 1981. A rapid method for the determination of arabinoxylans in wheat flours. Food Chem. 7:139-145.

-Geera, B. P., Nelson, J. E., Souza, E., and Huber, K. C. 2006. Granule bound starch synthase I (GBSSI) gene effects related to soft wheat flour/starch characteristics and properties. Cereal Chem. 83:544-550.

Garimella Purna, S. K., Miller, R. A., Seib, P. A., Graybosch, R. A., and Shi, Y.-C. 2011. Volume, texture, and molecular mechanism behind the collapse of bread made with different levels of hard waxy wheat flours. J. Cereal Sci. 54:37-43.

Grant, L. A., Vignaux, N., Doehlert, D. C., McMullen, M. S., Elias, E. M., and Kianian, S. 2001. Starch characteristics of waxy and nonwaxy tetraploid (Triticum turgidum L. var. durum) wheats. Cereal Chem. 78:590-595.

Graybosch, R. A. 1998. Waxy wheats: Origin, properties, and prospects. Trends Food Sci. Technol. 9:135-142.

Graybosch, R. A. 2005. Development and characterization of waxy winter wheats. Pages 113-122 in: Third International Wheat Quality Conference Proceedings. O. K. Chung and G. L. Lookhart, eds. AACC International: St. Paul, MN.

Graybosch, R. A., Guo, G., and Shelton, D. R. 2000. Aberrant falling numbers of waxy wheats independent of $\alpha$-amylase activity. Cereal Chem. 77:1-3.
Graybosch, R. A., Souza, E., Berzonsky, W., Baenziger, P. S., and Chung, O. K. 2003. Functional properties of waxy wheat flours: Genotypic and environmental effects. J. Cereal Sci. 38:69-76.

Guan, L. 2008. Wet milling of waxy wheat flours and characteristics of waxy wheat starch. Master's thesis. Kansas State University: Manhattan, KS.

Guan, L., Seib, P. A., Graybosch, R. A., Bean, S., and Shi, Y.-C. 2009. Dough rheology and wet milling of hard waxy wheat flours. J. Agric. Food Chem. 57:7030-7038.

Hamaker, B. R., and Griffin, V. K. 1993. Effect of disulfide bondcontaining protein on rice starch gelatinization and pasting. Cereal Chem. 70:377-380.

Hayakawa, K., Tanaka, K., Nakamura, T., Endo, S., and Hoshino, T. 1997. Quality characteristics of waxy hexaploid wheat (Triticum aestivum L.): Properties of starch gelatinization and retrogradation. Cereal Chem. 74: 576-580.

Hung, P. V., Maeda, T., and Morita, N. 2006. Waxy and high-amylose wheat starches and flours-Characteristics, functionality and application. Trends Food Sci. Technol. 17:448-456.

Ishida, N., Miura, H., Noda, T., and Yamauchi, H. 2003. Mechanical properties of white salted noodles from near-isogenic wheat lines with different wx protein-deficiency. Starch/Stärke 55:390-396.

-Kim, W., Johnson, J. W., Graybosch, R. A., and Gaines, C. S. 2003. Physicochemical properties and end-use quality of wheat starch as a function of waxy protein alleles. J. Cereal Sci. 37:195-204.

Leloup, V. M., Colonna, P., and Buleon, A. 1991. Influence of amyloseamylopectin ratio on gel properties. J. Cereal Sci. 13:1-13.

Maningat, C. C., Seib, P. A., Bassi, S. D., Woo, K. S., and Lasater, G. D. 2009. Wheat starch: Production, properties, modification and uses. Pages 441-510 in: Starch Chemistry and Technology. J. N. BeMiller and R. L. Whistler, eds. Academic Press: New York, NY.

-Mariotti, M., Zardi, M., Lucisano, M., and Pagani, M. A. 2005. Influence of the heating rate on the pasting properties of various flours. Starch/Stärke 57:564-572.

Morita, N., Maeda, T., Miyazaki, M., Yamamori, M., Miura, H., and Ohtsuka, I. 2002. Dough and baking properties of high-amylose and waxy wheat flours. Cereal Chem. 79:491-495.

Morris, C. F., Bettge, A. D., Giroux, M. J., Zeng, M., and King, G. E. 1998. Relationships between RVA pasting characteristics and amylose content of normal, partially-waxy, and waxy wheat flours and starches. Pages 323-327 in: Cereals '98: Proceedings of the 48th Australian Cereal Chemistry Conference. L. O'Brien, A. B. Blakeney, A. S. Ross, and C. W. Wrigley, eds. RACI: Melbourne, Australia.

Reddy, I., and Seib, P. A. 2000. Modified waxy wheat starch compared to modified waxy corn starch. J. Cereal Sci. 31:25-39.

Sasaki, T., and Matsuki, J. 1998. Effect of wheat starch structure on swelling power. Cereal Chem. 75:525-529.

-Sasaki, T., Yasui, T., and Matsuki, J. 2000. Effect of amylose content on gelatinization, retrogradation, and pasting properties of starches from waxy and nonwaxy wheat and their F1 seeds. Cereal Chem. 77:58-63.

Sayaslan, A., Seib, P. A., and Chung, O. K. 2006. Wet-milling properties of waxy wheat flours by two laboratory methods. J. Food Eng. 72:167-178.

-Seib, P. A. 2000. Reduced-amylose wheats and Asian noodles. Cereal Foods World 45:504-512.

Tester, R. F., and Morrison, W. R. 1990. Swelling and gelatinization of cereal starches. I. Effects of amylopectin, amylose, and lipids. Cereal Chem. 67:551-557.

Tester, R. F., and Morrison, W. R. 1992. Swelling and gelatinization of cereal starches. III. Some properties of waxy and normal nonwaxy barley starches. Cereal Chem. 69:654-658.

-Wang, L., and Flores, R. A. 2000. Effects of flour particle size on the textural properties of tortilla flours. J. Cereal Sci. 31:263-272.

-Yasui, T., Matsuki, J., Sasaki, T., and Yamamori, M. 1996. Amylose and lipid content, amylopectin structure, and gelatinization properties of waxy wheat (Triticum aestivum) starch. J. Cereal Sci. 24:131-137.

-Yasui, T., Sasaki, T., and Matsuki, J. 1999. Milling and flour pasting properties of waxy endosperm mutant lines of bread wheat (Triticum aestivum L.). J. Sci. Food Agric. 79:687-692.

-Yoo, S., and Jane, J. 2002. Structural and physical characteristics of waxy and other wheat starches. Carbohydr. Polym. 49:297-305.

Zhu, L.-J., Liu, Q.-Q., Sang, Y., Gu, M.-H., and Shi, Y.-C. 2010. Underlying reasons for waxy rice flours having different pasting properties. Food Chem. 120:94-100.

[Received October 16, 2014. Accepted May 11, 2015.] 